\title{
Blood-ethanol levels predict amount of ethanol consumption by rats
}

\author{
STEVEN BELENKO and STEPHEN C. WOODS \\ Columbia University, New York, New York 10027
}

\begin{abstract}
A previous report that low-drinker rats develop higher peak blood-ethanol levels than high-drinker rats following intraperitoneal ethanol is confirmed. Further, a strong correlation occurred between blood-ethanol levels in naive rats and subsequent free-choice ethanol intake.
\end{abstract}

The search for correlations between physiological and behavioral measures is an important consideration in developing animal models of alcoholism. It will be useful to be able to specify the relationships between free-choice ethanol intake by rats and such factors as caloric value, absorption rate, blood-alcohol levels, etc. The present experiment shows that the amount of free-choice ethanol consumed by rats can be reliably predicted from the results of an acute blood-ethanol test administered to the rats prior to their consumption of ethanol.

\section{EXPERIMENT I}

Recently, we reported that rats selected on the basis of consuming relatively large quantities (high drinkers) or relatively small quantities (low drinkers) of ethanol differ in their response to an injection of ethanol (Belenko \& Woods, 1973); i.e., low drinkers had significantly higher blood-ethanol levels $15 \mathrm{~min}$ after an intraperitoneal (IP) injection than did high drinkers. In the first experiment reported here, these findings were replicated. A group of 254 -month-old Charles River Wistar male albino rats, housed in individual cages, were offered a choice between an ethanol solution and water for 15 days. The positions of the two drinking tubes plus a third blank tube, were randomly switched daily in order to control for position bias (Myers \& Holman, 1966). The ethanol solution was offered in increasing concentrations from $3 \%$ to $17 \%$ in water (v/v), increasing $1 \%$ per day. A group of 5 high and 5 low drinkers ${ }^{1}$ was selected from the original 25 rats on the basis of average amount of absolute ethanol consumed per day, and the daily ratio of ethanol to total fluid consumed. The mean daily intakes (in $\mathrm{g} / \mathrm{kg} /$ day) of absolute ethanol were $1.00 \pm 0.17(\mathrm{M} \pm \mathrm{SEM})$ and $3.66 \pm 0.25$ for the low and high drinkers, respectively. The daily intake of high drinkers was lower than is generally reported for

Supported by NIH Grant AM 17112 to S. C. Woods. Requests for reprints should be addressed to S. Belenko, Vera Institute of Justice, 292 Madison Avenue, New York, New York 10017. S. C. Woods is now at the Department of Psychology, University of Washington, Seattle, Washington 98195.

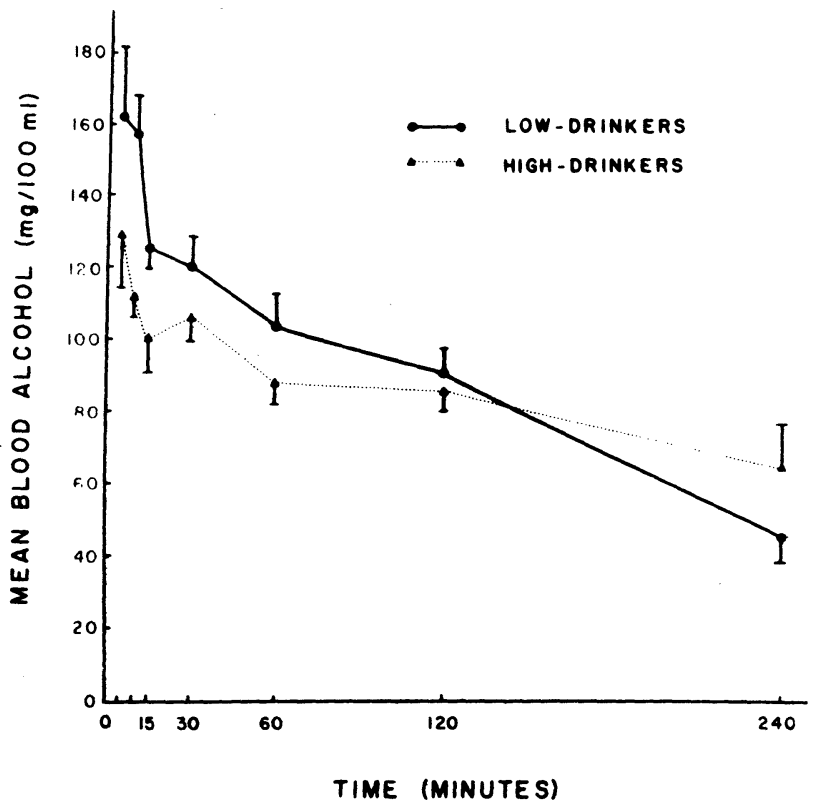

Figure 1. Blood-ethanol levels $(M \pm S E M)$ for high-drinker and low-drinker rats following IP administration of $1.2 \mathrm{~g} / \mathrm{kg}$ of ethanol.

"high-preference" rat strains (e.g., Eriksson, 1972).

Beginning 24 days following this selection period, the 10 rats were given an IP injection of $1.2 \mathrm{~g} / \mathrm{kg}$ of ethanol in a $20 \%(\mathrm{v} / \mathrm{v})$ solution with isotonic saline. Blood samples were taken from the tip of the tail prior to and at $5,10,15,30,60,120$, and $240 \mathrm{~min}$ after the injection. The blood was immediately assayed for ethanol by the distillation method of Lester and Greenberg (1958). Three such acute ethanol tests, spaced at least 2 days apart, were given to each rat. The results are summarized in Figure 1. Low drinkers had a higher level of ethanol in the blood in the 15 -min period after the injection, confirming the previous results (Belenko \& Woods, 1973). There were no differences between the two curves after $60 \mathrm{~min}$, again confirming previous reports (Segovia-Riquelme, Campos, Solodkowska, Gonzalez, Alvarado, \& Mardones, 1962; Segovia-Riquelme, Vitale, Hegsted, \& Mardones, 1956). 


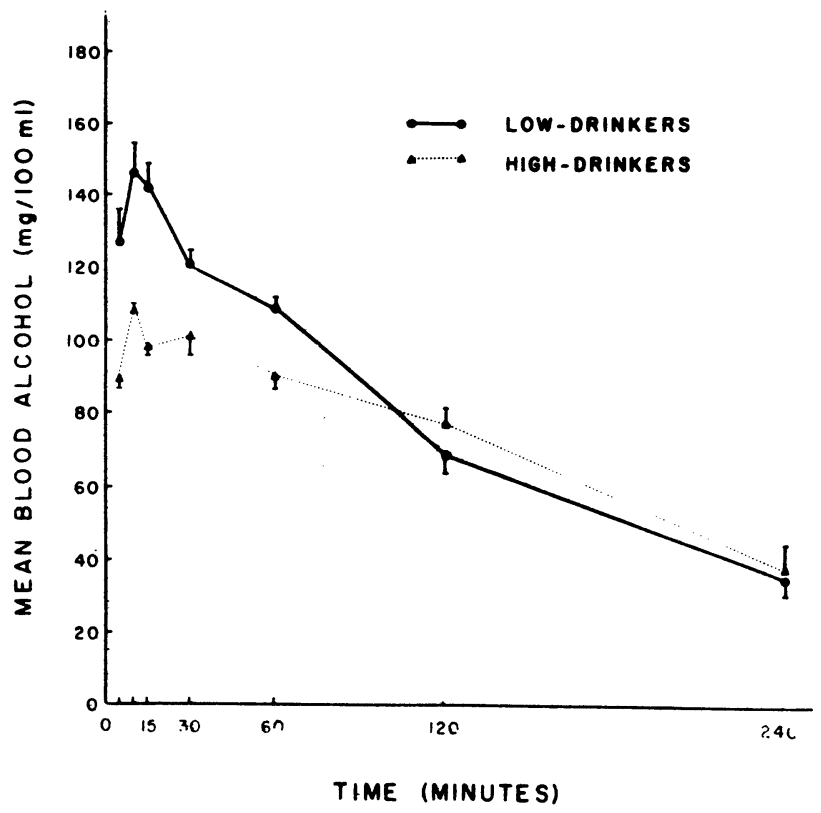

Figure 2. Blood-ethanol levels $(M \pm S E M)$ for high-drinker and low-drinker rats following IP administration of $1.2 \mathrm{~g} / \mathrm{kg}$ of ethanol.

\section{EXPERIMENT II}

It is possible that the lower early blood-ethanol levels attained by the high drinkers were a function of their previous ethanol consumption. A second experiment was therefore undertaken in which the order of the two portions of the experiment was reversed, i.e., the rats were given acute ethanol tests prior to any ethanol consumption. In the experiment, eight female Wistar rats, aged 11 weeks, were given IP ethanol tests in the manner described above. Ten days later, they were offered a choice between $5 \%$ ethanol in water $(\mathrm{v} / \mathrm{v})$ and tap water, for a period of 10 days. From the original group of eight rats, three low drinkers $(0.66$ $\pm .10 \mathrm{~g} / \mathrm{kg} / \mathrm{day}$ consumed) and three high drinkers $(2.85 \pm .18)$ (the "extreme" ends of the distribution) were selected. The blood-ethanol curves (obtained before the rats were classified as low or high drinkers) for these two grolups of rats are summarized in Figure 2. The blood-alcohol data for Experiments I and II were quite similar and were pooled for analysis of variance. The low drinkers had higher blood-ethanol levels during the 15-min period after the injection $(F=$ $8.14, \mathrm{df}=1,14, \mathrm{p}<.025)$ and again there were no reliable differences between the curves after $60 \mathrm{~min}$ postinjection $(\mathrm{F}=1.41, \mathrm{df}=1,14, \mathrm{p} \gg .1)$.

A perhaps more interesting finding is that the results of the acute ethanol tests were a reliable predictor of subsequent ethanol consumption. The eight rats were ranked from highest to lowest mean daily absolute ethanol intake, and from lowest to highest peak postinjection blood-ethanol level. The Spearman rank correlation was $0.833(\mathrm{p}<.02)$. Thus, the amount of ethanol subsequently consumed was inversely related to peak blood-ethanol levels following IP ethanol.

\section{DISCUSSION}

Although a causal relationship between bloodethanol levels and free-choice ethanol consumption has yet to be established, and the above results should not be generalized to other rat strains, some inferences can be suggested. High concentrations of blood-ethanol are toxic, and toxicity often leads to the formation of learned aversions to specific flavors (Revusky \& Garcia, 1970; Rozin \& Kalat, 1971). It is possible that the limited ethanol intake by low drinkers may be related to a relatively higher blood-alcohol level following their consumption of ethanol. If the results obtained in the present experiment with IP injections can be generalized to free-choice oral ethanol consumption, those rats which reach a higher degree of toxicity (as reflected by higher blood-ethanol levels) should more readily develop an aversion to consuming the ethanol. However, it has not yet been demonstrated that the blood alcohol levels attained via oral consumption by the rats in these experiments can induce a learned aversion.

In an earlier study (Lotter, Weisinger, Decke, Vasselli, \& Woods, Note 1), a low IP dose of ethanol $(0.8 \mathrm{~g} / \mathrm{kg})$ was found to lead to a learned aversion to flavors associated with the ethanol. In contrast, Lester, Nachman, and Le Magnen (1970) did not induce a learned aversion to saccharin using stomach loading with a relatively high dose of ethanol $(2.4 \mathrm{~g} / \mathrm{kg})$ as the aversive stimulus.

The above results suggest the possibility of a relationship between free-choice ethanol intake and a physiological response to the drug in rats.

\section{REFERENCE NOTE}

1. Lotter, E. C., Weisinger, R. S., Decke, E., Vasselli, J. R., \& Woods, S. C. Ethanol: Shift from aversive to rewarding agent with increased prior experience. Paper presented at meeting of the Western Psychological Association, San Francisco, California, 1974.

\section{REFERENCES}

Belenko, S., \& Woods, S. C. Physiological correlates of ethanol self-selection by rats. Physiological Psychology, 1973, 1, 155-157.

ERIKsson, K. Behavioral and physiological differences among rat strains specially selected for their alcohol consumption. In F. Seixas et al. (Eds.), Nature and nurture in alcoholism. Annals of the New York Academy of Sciences, 1972, 197.

Lester, D., \& Greenberg, L. A. The determination of ethanol in biological materials. Quarterly Journal of Studies on Alcohol, 1958, 19, 331-335.

Lester, D., Nachman, M., \& Le Magnen, J. Aversive conditioning by ethanol in the rat. Quarterly Journal of Studies on Alcohol, 1970, 31, 578-586. 
Myers, R. D., \& Holman, R. B. A procedure for eliminating position habit in preference-aversion tests for ethanol and other fluids. Psychonomic Science, 1966, 5, 6-7.

ReVusKy, S. H., \& GaRCIA, J. Learned associations over long delays. In G. Bower \& J. T. Spence (Eds.), The psychology of learning and motivation: Advances in research and theory. New York: Academic Press, 1970, 4, 1-84.

Rozin, P., \& Kalat, J. W. Specific hungers and poison avoidance as adaptive specializations in learning. Psychological Review, 1971, 78, 459-486.

Segovia-Riquelme, N., Campos, I., Solodxowska, W. Gonzalez, G., Alvarado, R., \& Mardones, J. Metabolism of labeled ethanol, acetate, pyruvate, and butyrate in "drinker" and "non-drinker" rats. Journal of Biological Chemistry, 1962, 237, 2038-2040.
Segovia-Riquelme, N., Vitale, J. J., Hegsted, D. M., \& Mardones, J. Alcohol metabolism in "drinking" and "nondrinking" rats. Journal of Biological Chemistry, 1956, 223, 399-403.

\section{NOTE}

1. Those with highest and lowest consumption.

(Received for publication March 11, 1975; accepted May 8, 1975.) 